\title{
The Use of Critical Solution Mixtures for Contaminated Sediments Remediation
}

Tal Golan ${ }^{1}$, Zvi Ludmer ${ }^{1}$, Elena Ermolenko1, Neima Brauner $^{2}$ and Amos Ullmann ${ }^{2}$

1 Faculty of Agriculture, The Hebrew University, Rehovot 2 Faculty of Engineering, Tel Aviv University, Tel Aviv 


\section{The problem:}

\section{Polluted sediments in the Kishon River, Israel}

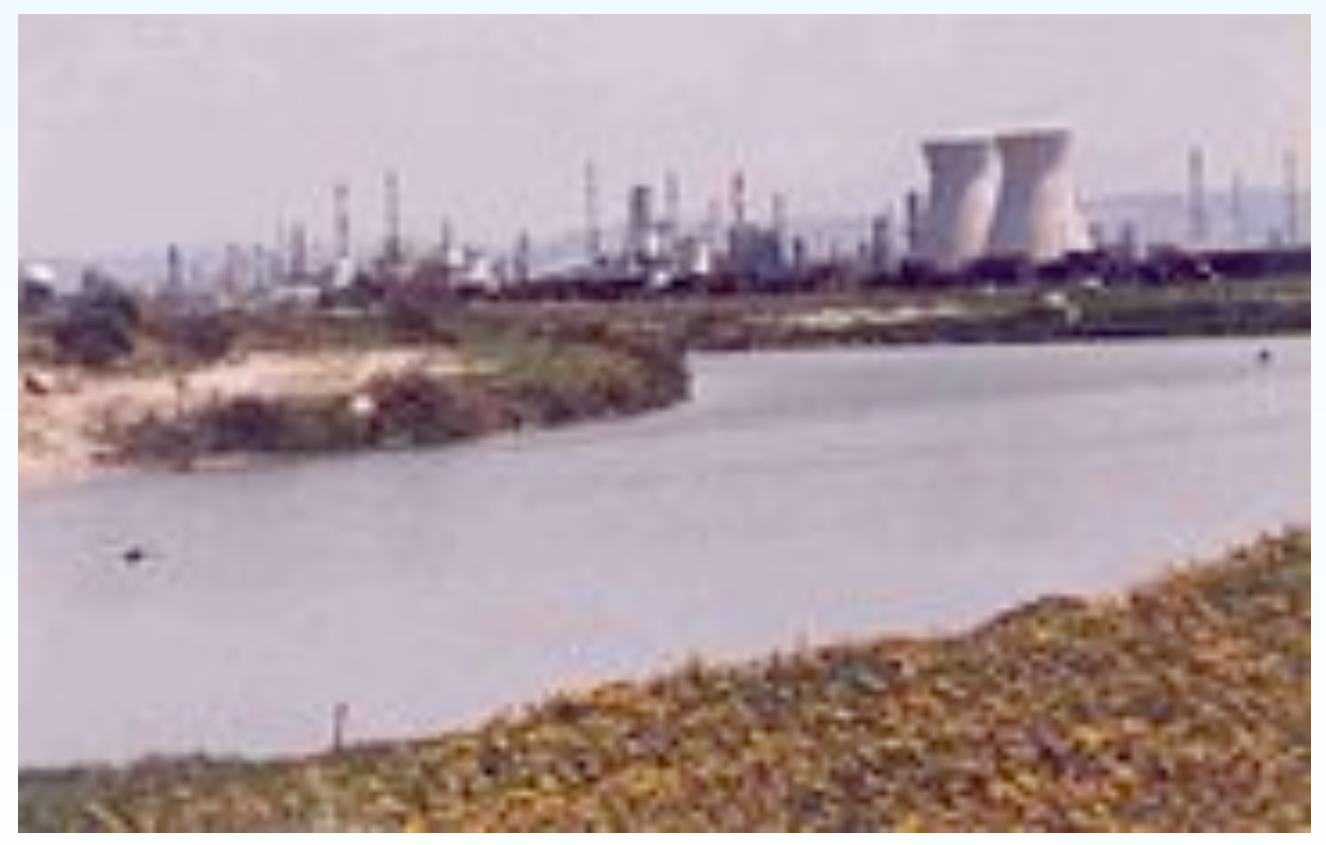




\section{Sediment composition at both ends of the Kishon River}

Kfar Yehushua

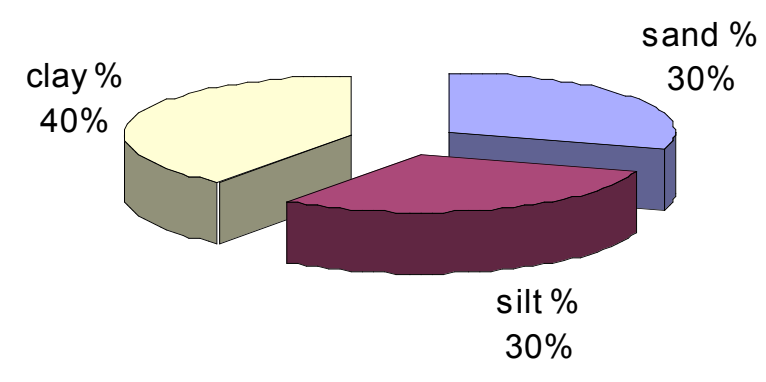

\author{
Haifa industrial zone
}

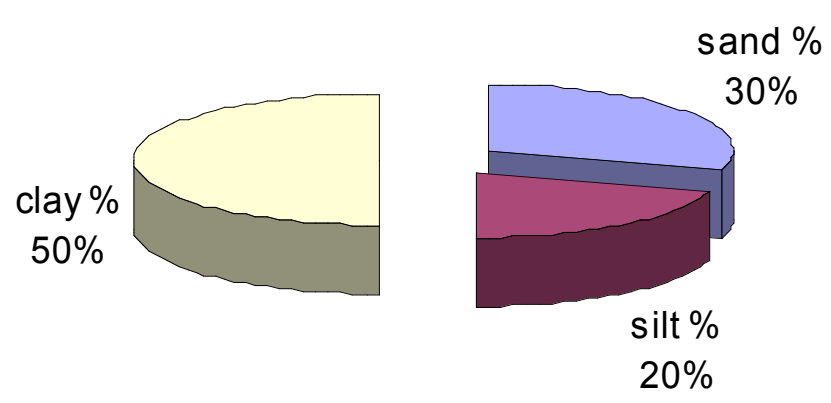

\section{Pollution: heavy metals and organic pollutants}




\section{Concept of extraction using critical solution mixtures}

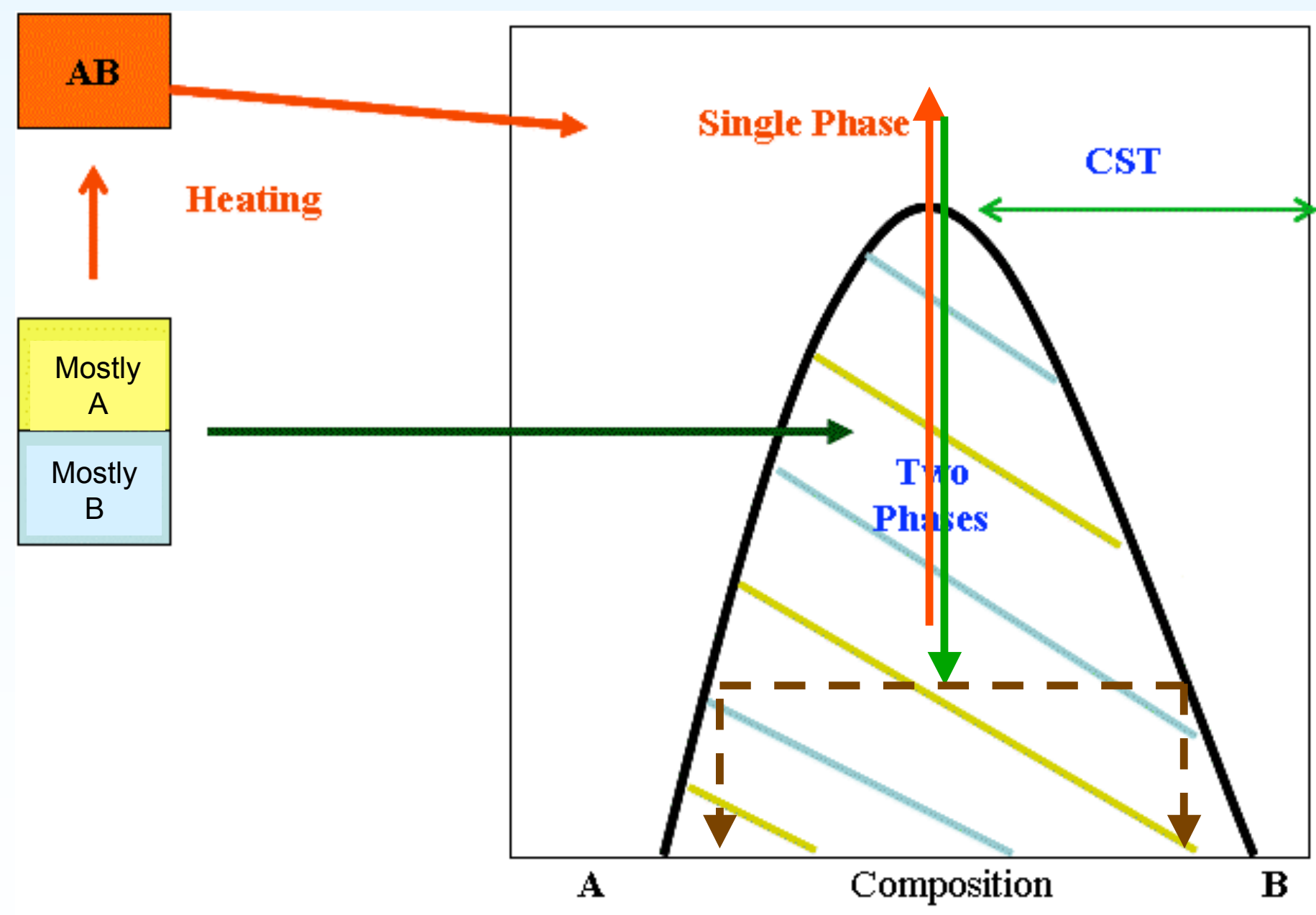

Phase A: Water

Phase B: Organic solvent 


\section{Phase separation mechanisms}

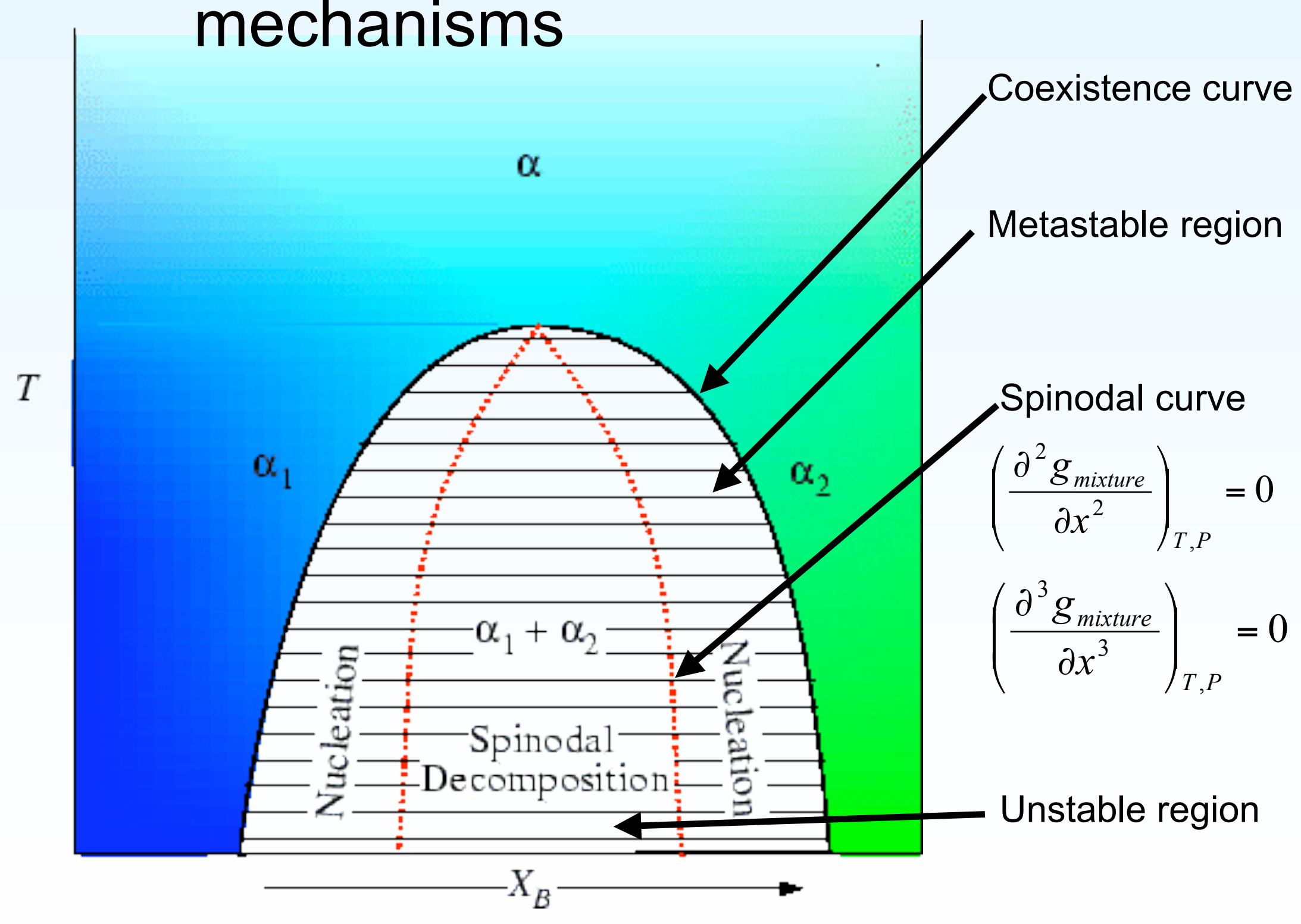




\section{Why Use Critical Solution Mixtures?}

- Using water as one of the mixture components enables the formation of one phase with the water inside the solid particles.

- Superior penetration of the organic solvent of the mixture into the solid pores.

- Enables contact, almost on a molecular level, between the extracting system and the target pollutants.

- On slight temperature change phase separation is achieved. 


\section{Experimental setup}

Contaminated dry sediments

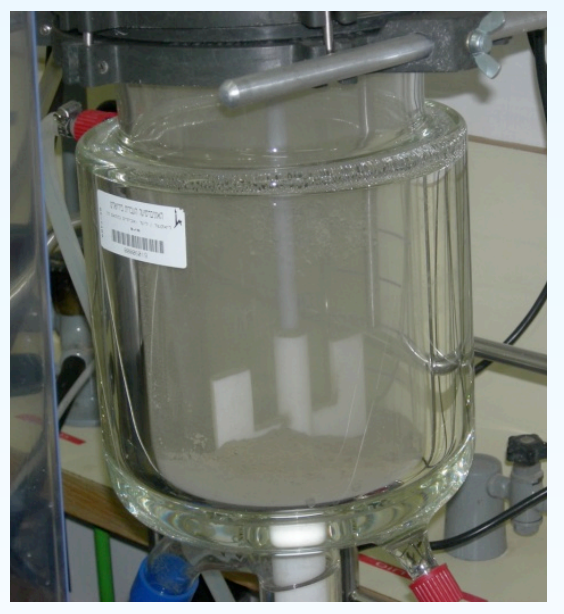

Mixing with solvents at elevated

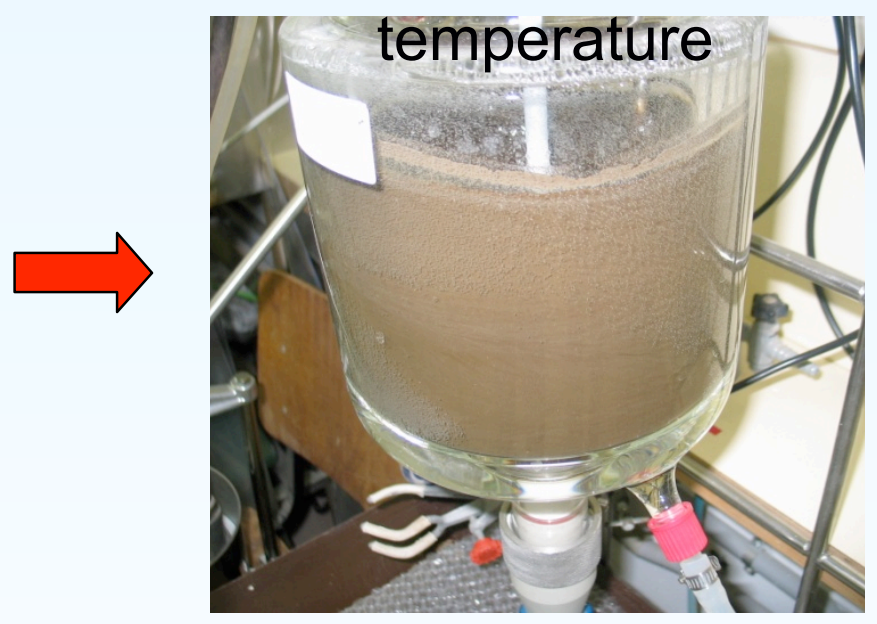

Decontaminated wet sediments

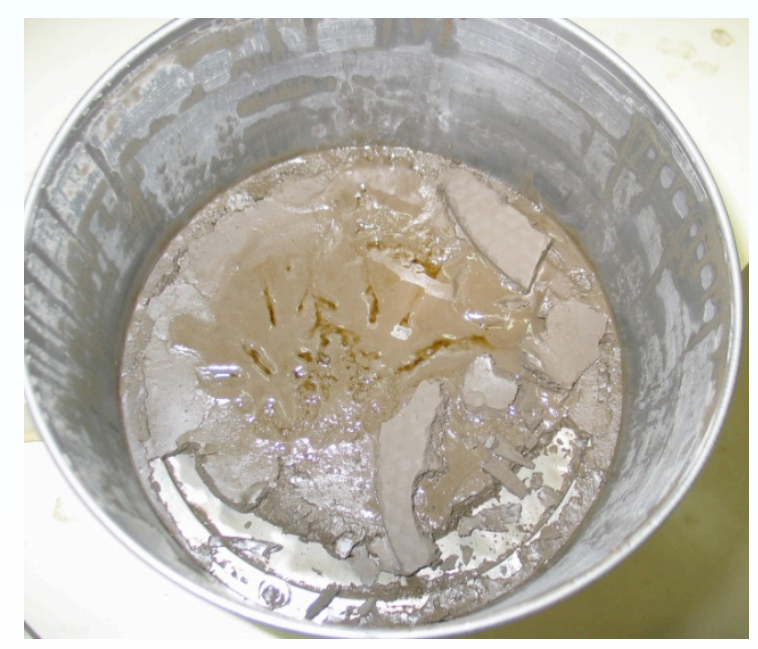

Phase separation at room temperature
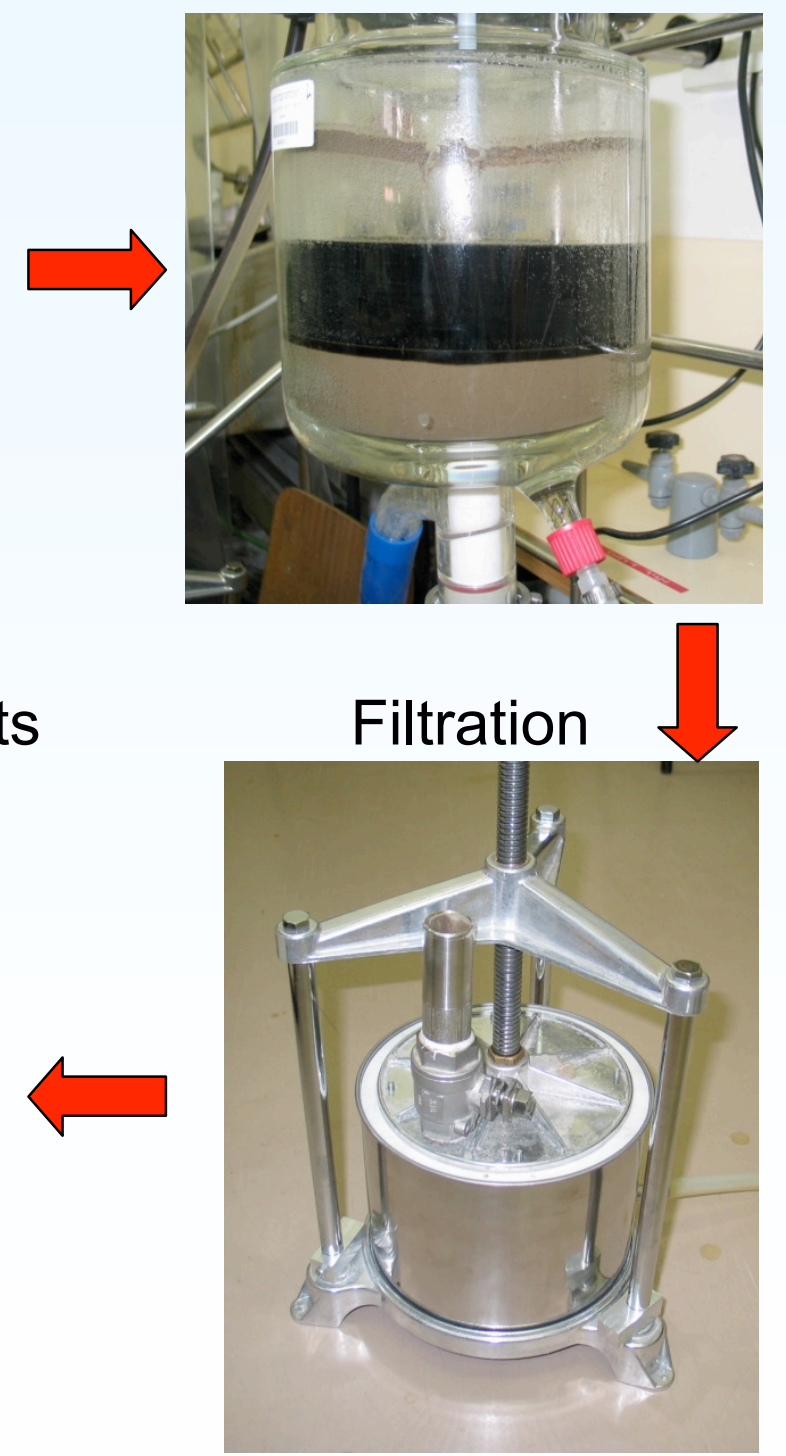


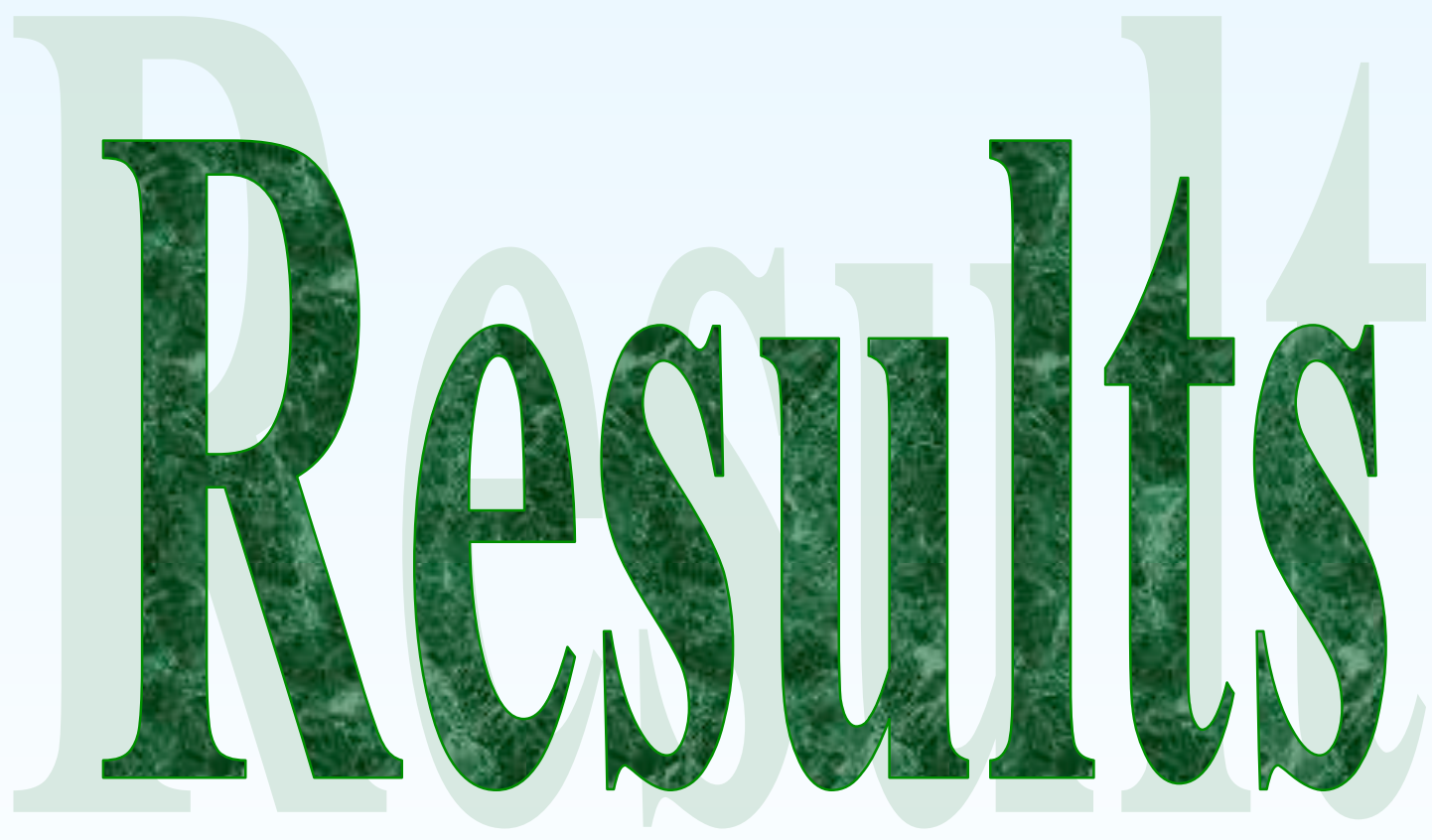




\section{Heavy metals extraction with Ammonium diethyldithiocarbamate (ADDC) using critical solution mixture}

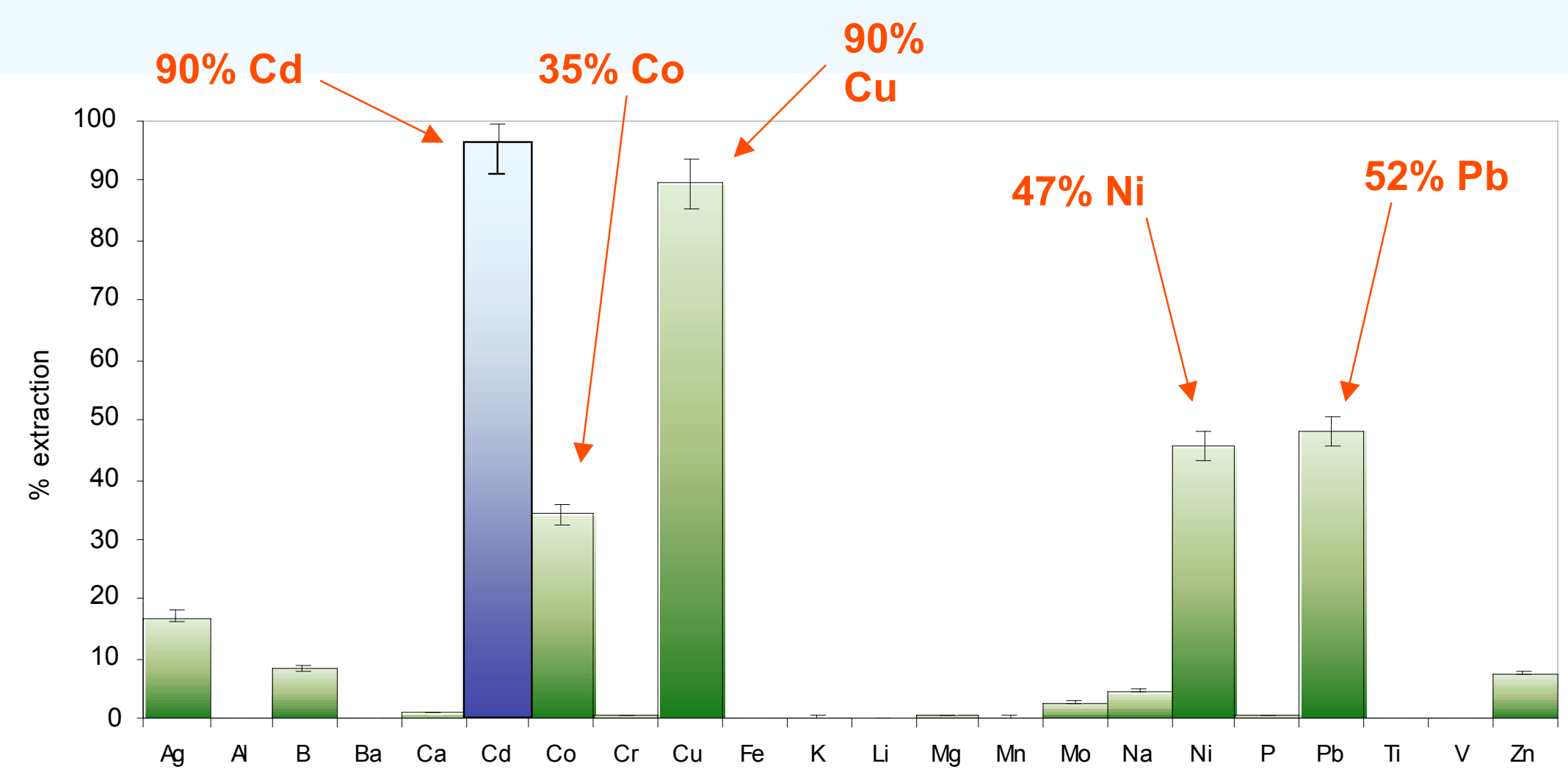


Kinetics of cadmium extraction : A comparison between extraction via heating-cooling cycle (a) and isothermal extraction (b)

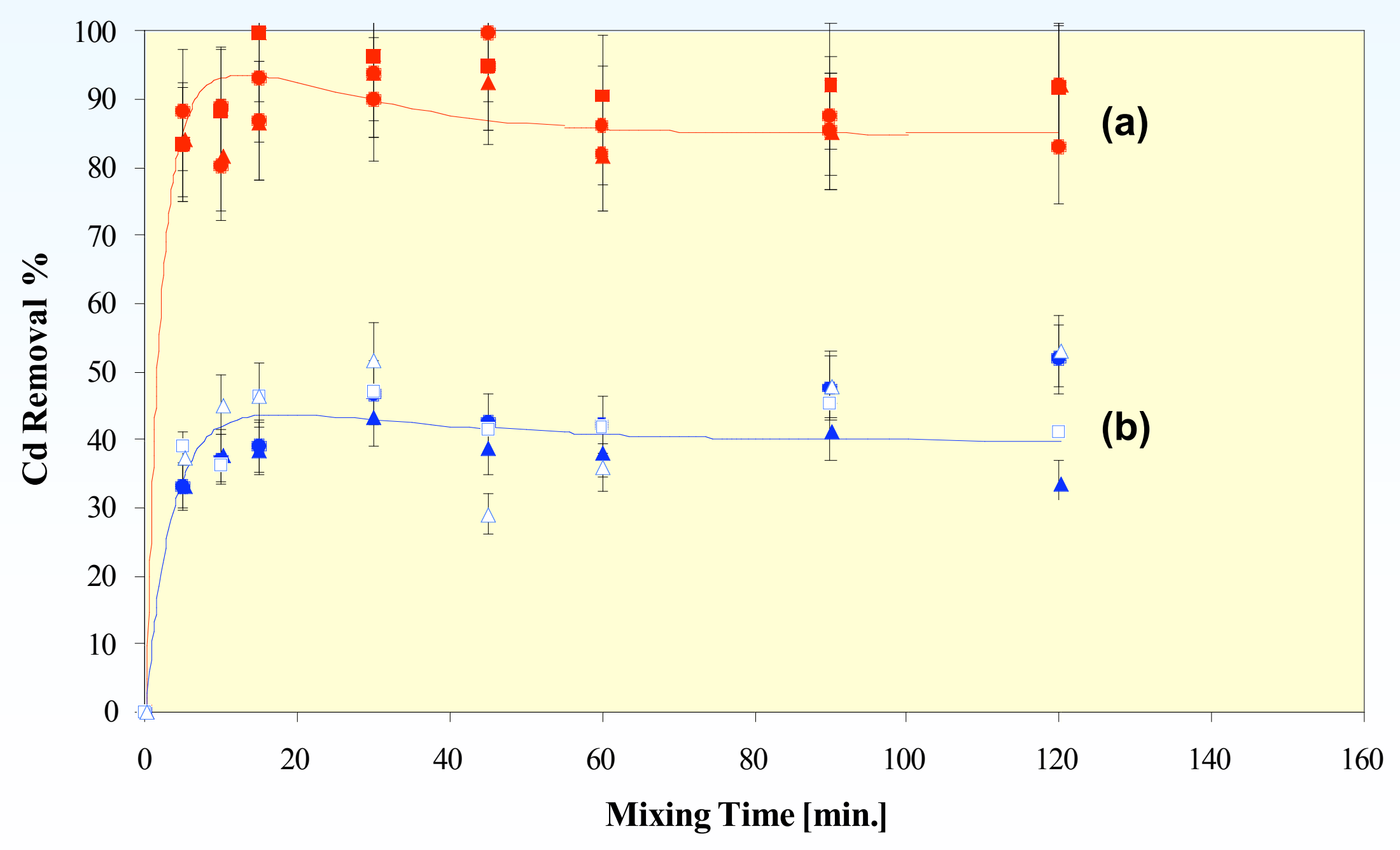


Isothermal mixing
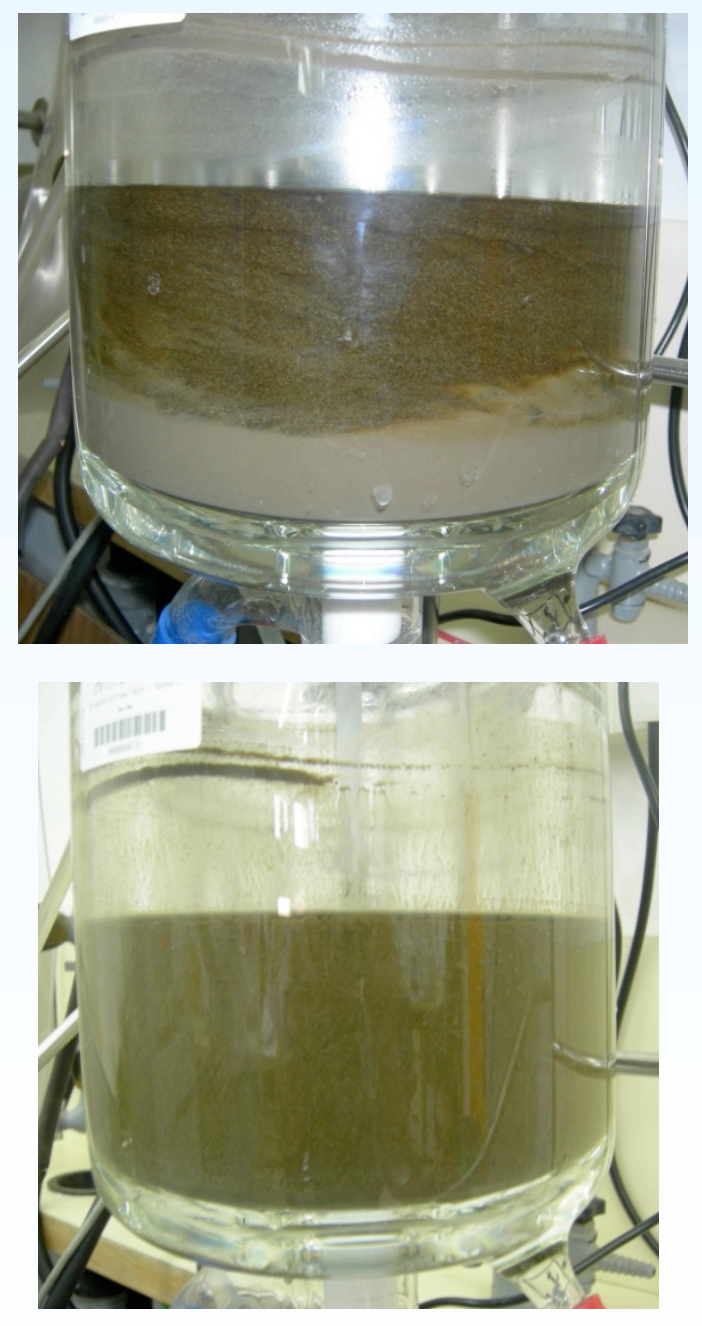

Phase transition
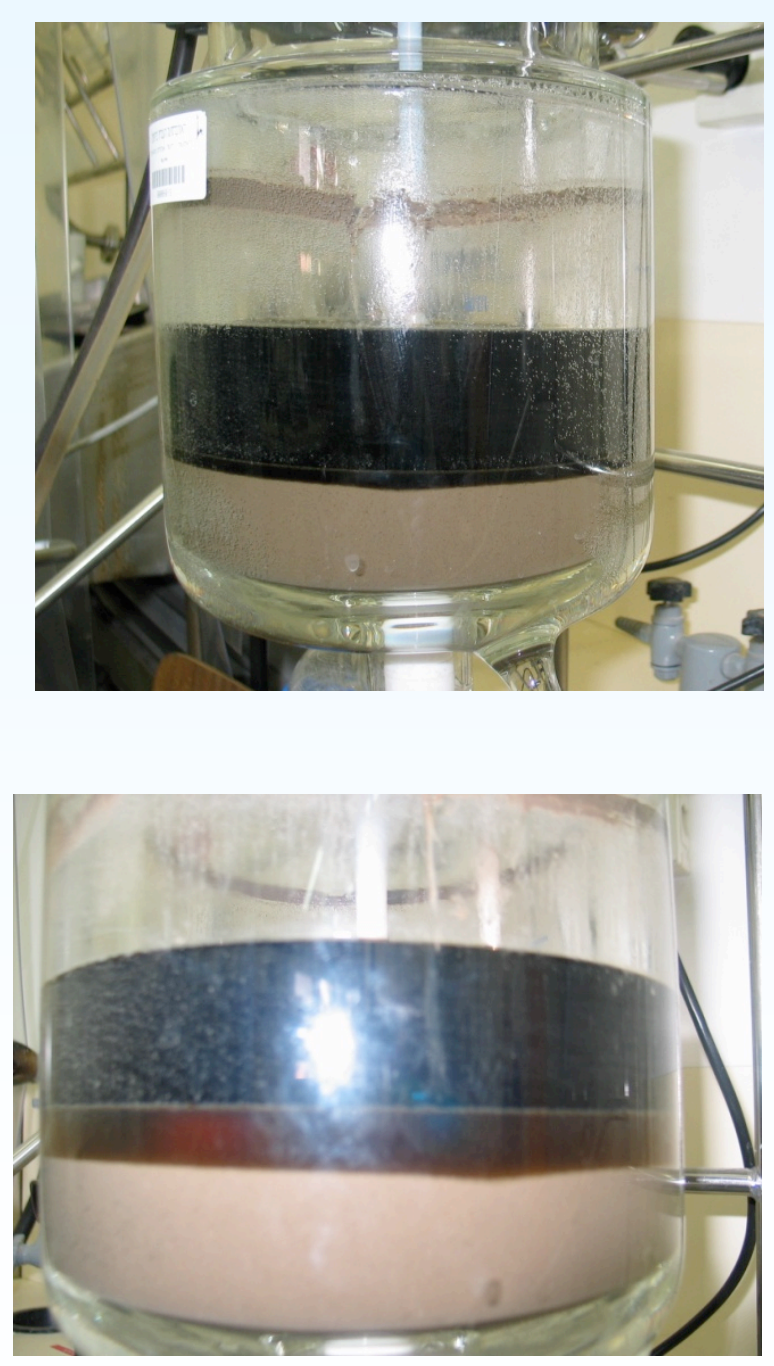


\section{The use of different solution mixtures for heavy metals extraction with ADDC}

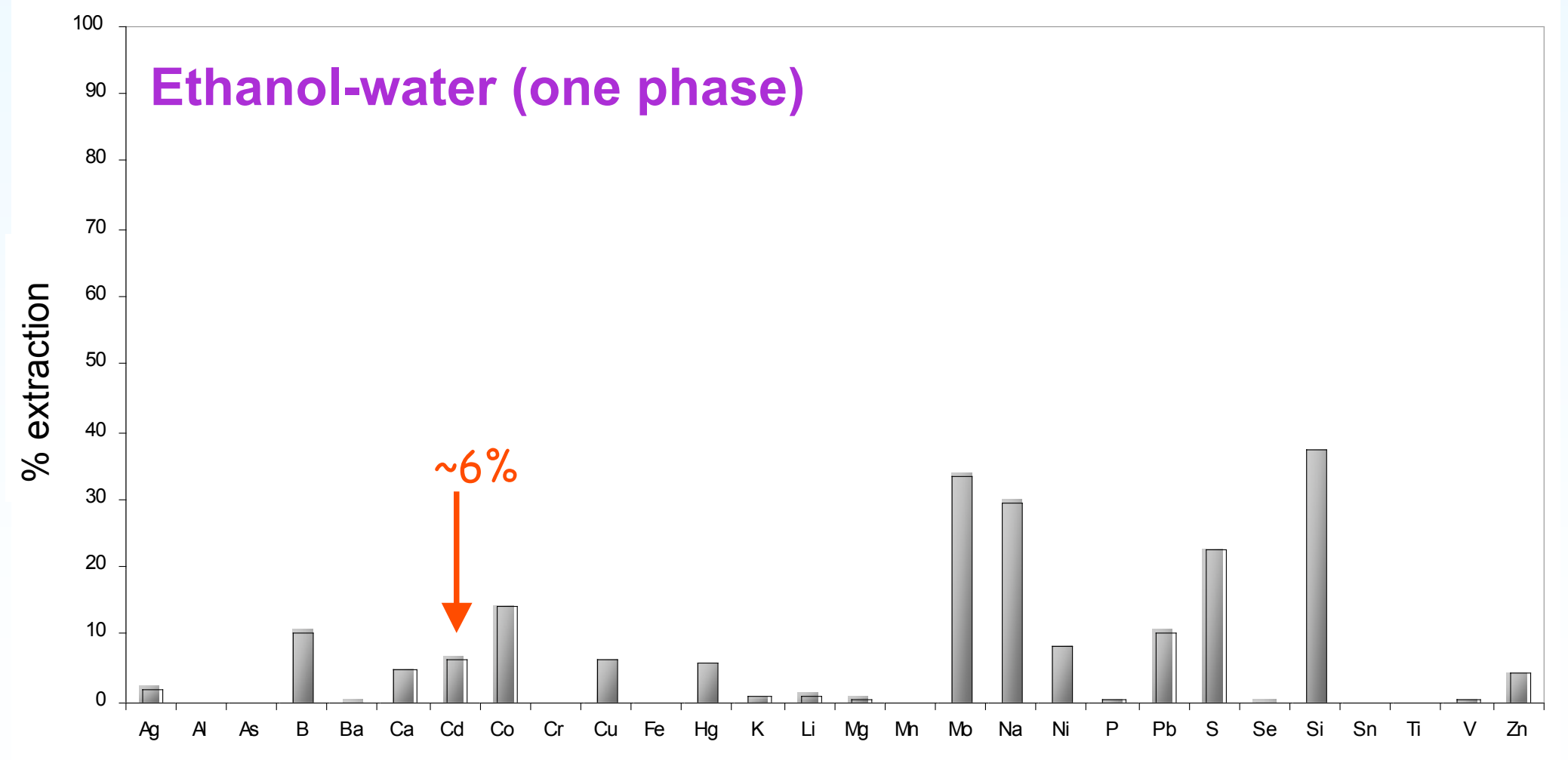



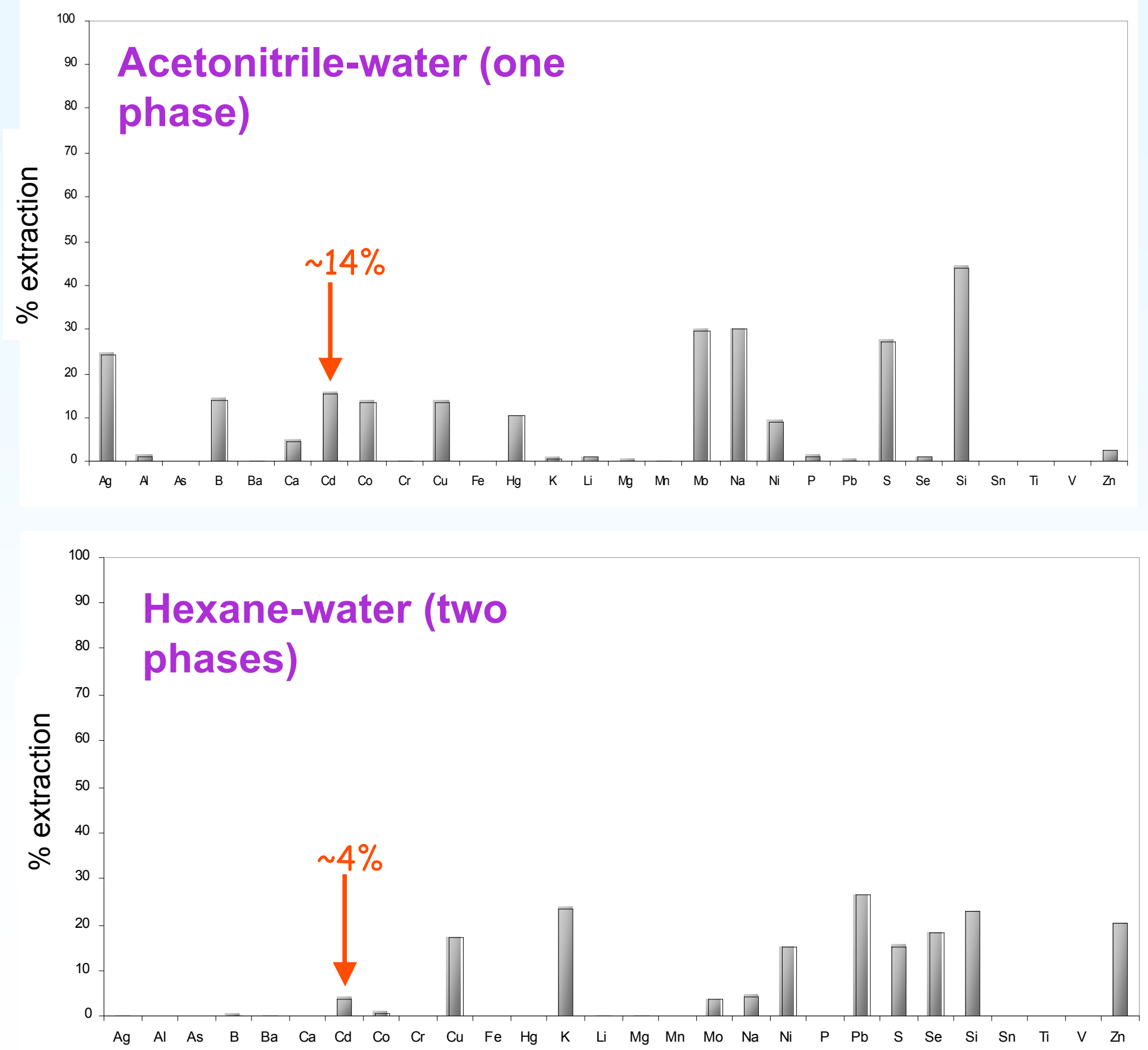


\section{Possible mechanism of extraction}

Heating and cooling

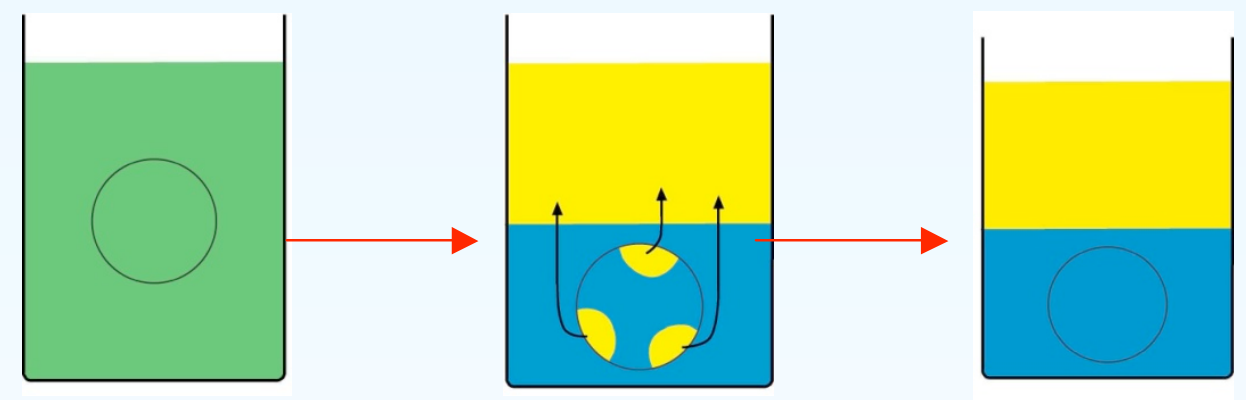

Isothermal

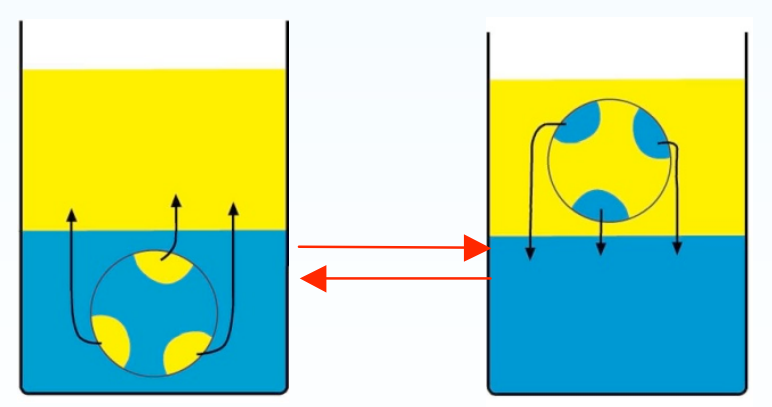

Conclusion: Extraction occurs during phase separation 


\section{Organic Pollutants extraction using critical solution mixtures, compared to Soxhlet extraction (preliminary results)}

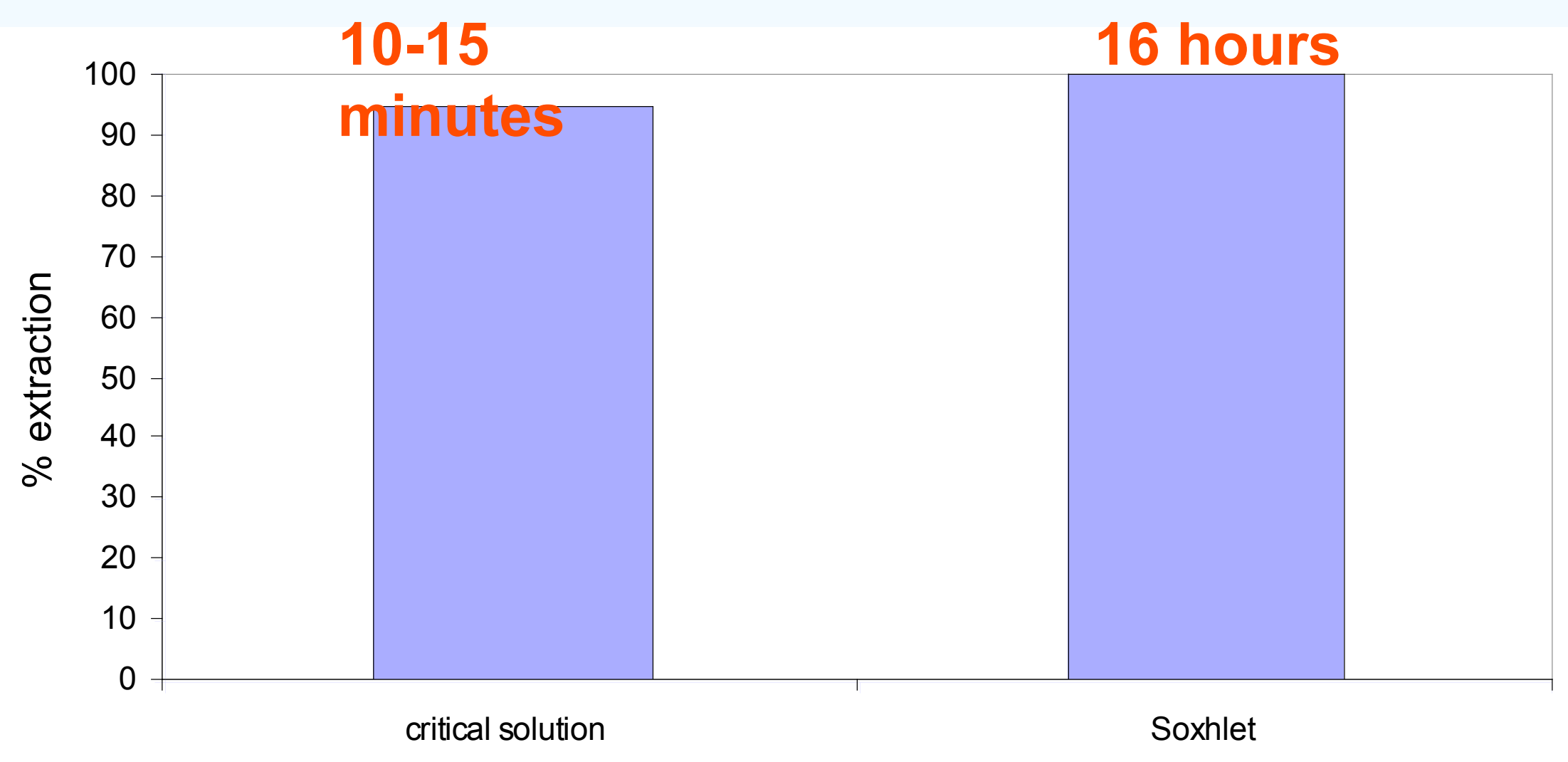




\section{Summary}

Using the critical solution mixture, at the mode of heating and cooling, it was possible to extract close to $90 \%$ of the cadmium from the Kishon's sediments, in a single cycle of 10-15 minutes.

T3 The organic pollutants were simultaneously extracted and directed into the mainly organic phase.

B By the use of an appropriate chelating agents, it is possible to direct the heavy metals towards the mainly organic or aqueous phase. 

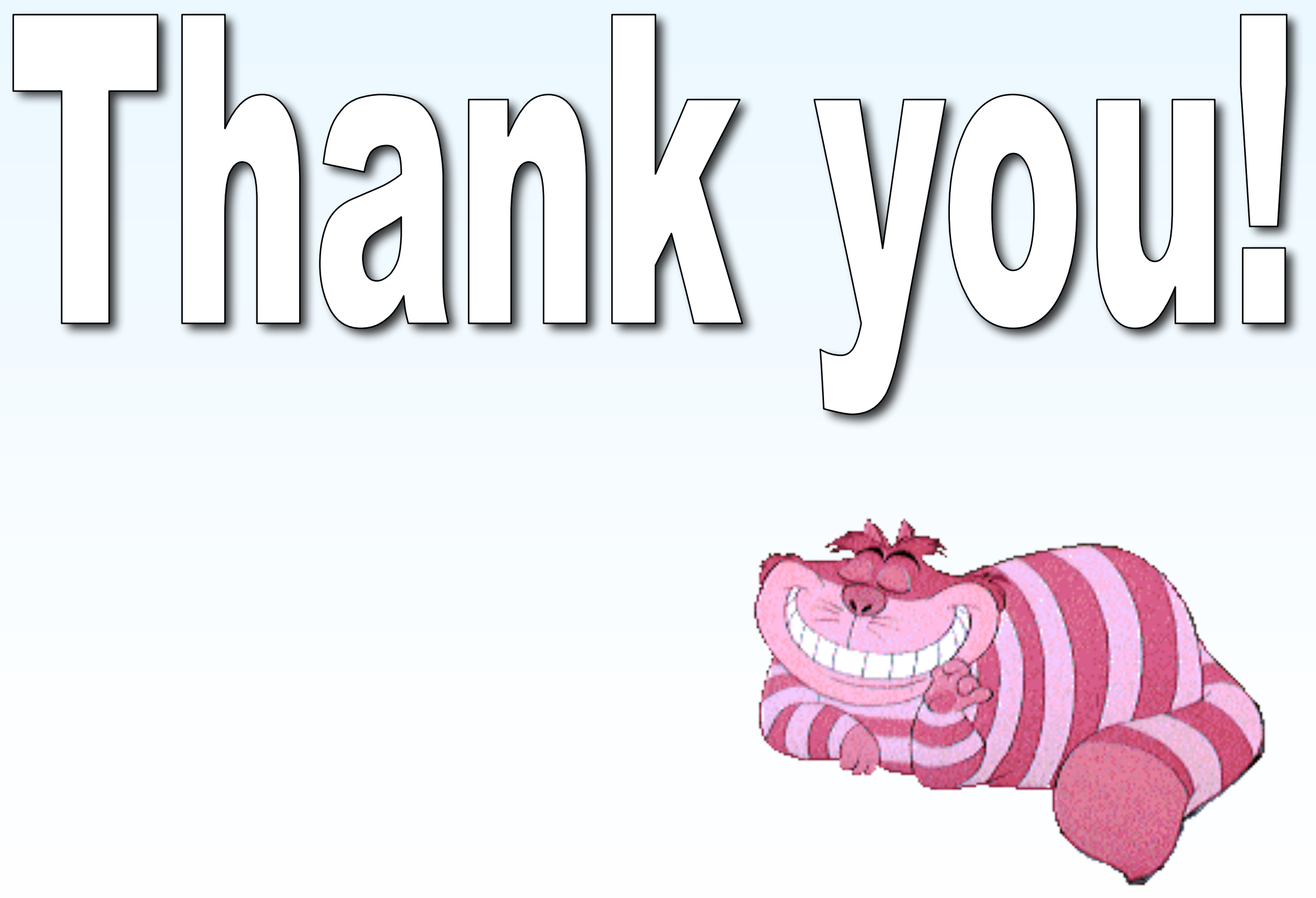


\section{References}

Abumaizar, R. \& Khan, L. I. Laboratory investigation of heavy metal removal by soil washing. Journal of the Air \& Waste Management Association 46, 765-768 (1996).

Askvik, K. M., Høiland, S., Fotland, P., Barth, T., Grønn, T. \& Fadnes, F.H. Calculation of wetting angles in crude oil/water/quartz systems. Journal of Colloid and Interface Science 287, 657-663 (2005).

Atanassova, D., Sttefanova, V. \& Russeva, E. Co-Precipitative Pre-concentration with Sodium diethyldithiocarbamate and ICP-AES of $\mathrm{Se}, \mathrm{Cu}, \mathrm{Pb}, \mathrm{Zn}, \mathrm{Fe}, \mathrm{Co}, \mathrm{Ni}, \mathrm{Mn}, \mathrm{Cr}$ and Cd in water. Talanta 47, 1237-1243 (1998).

Atanassova, I. \& Brummer, G. W. Polycyclic Aromatic hydrocarbons of anthropogenic and biopedogenic origin in a colluviated hydromorphic soil of western Europe. Geoderma 120, 27-34 (2004).

Barahona, M. V. \& Sánchez-Fortún, S. Toxicity of carbamates to the brine shrimp Artemia salina and the effect of atropine, BW284c51, iso-OMPA and 2-PAM on carbaryl toxicity. Environmental Pollution 104, 469-476 (1999).

Bonamico, M., Dessy, G., Mugnoli, A., Vaciago, A. \& Zambonelli, L. Structural studies of metal dithiocarbamates. II. The crystal and molecular structure of copper diethyldithiocarbamate. Acta Crystallographica 19, 886-897 (1965).

Bonamico, M., Mazzone, G., Vaciago, A. \& Zambonelli, L. Structural studies of metal dithiocarbamates. III. The crystal and molecular structure of zinc diethyldithiocarbamate. Acta Crystallographica 19, 898-909 (1965). 
Cahn, J.W. On spinodal decomposition. Acta Metallurgica 9, 795-801 (1961).

Calace, N., Campanella, L., Palombo, R., Petronio, B. M. \& Pupella, A. Soil characteristics studied by electrophoresis in stabilized medium. The Science of the Total Environment 219, 7-12 (1998).

Chaiyaraksa, C. \& Sriwiriyanuphap, N. Batch washing of cadmium from soil and sludge by a mixture of Na2S2O5 and Na2EDTA. Chemosphere 56, 1129-1135 (2004).

Chen, L., Knackstedt, M., Robert, M. \& Shukla, K. P. Fluid interface in two dimensions close to the critical point. Physica A 172, 53-76 (1991).

Chung, H. I. \& Kamon, M. Ultrasonically enhanced electrokinetic remediation for removal of $\mathrm{Pb}$ and phenanthrene in contaminated soils. Engineering Geology 77, 233242 (2005).

Czachor, $\mathrm{H}$. Modelling the effect of pore structure and wetting angles on capillary rise in soils having different wettabilities. Journal of Hydrology 328, 604-613 (2006).

Dasgupta, S., Meisner, C., Wheeler, D., Xuyen, K. \& Thi Lam, N. Pesticide poisoning of farm workers - implications of blood test results from Vietnam. International Journal of Hygiene and Environmental Health 210, 121-132 (2007).

Di Palma, L., Ferrantelli, P., Merli, C. \& Biancifiori, F. Recovery of EDTA and metal precipitation from soil flushing solutions. Journal of Hazardous Materials B103, 153-168 (2003).

Di Palma, L. \& Ferrantelli, P. Copper leaching from a sandy soil: Mechanism and parameters affecting EDTA extraction. Journal of Hazardous Materials B122, 85-90 (2005).

Di Palma, L., Ferrantelli, P. \& Medici, F. Heavy metals extraction from contaminated soil: Recovery of the flushing solution. Journal of Environmental Management 77, 205211 (2005). 
Domenicano, A., Torelli, L., Vaciago, A. \& Zambonelli, L. Structural studies of metal dithiocarbamates. Part IV. The crystal and molecular structure of cadmium(II) NNdiethyldithiocarbamate. Journal of the Chemical Society A: Inorganic, Physical, Theoretical, 1351-1361 (1968).

Eliyahu, N., Hennis, I. \& Ludmer, Z. in AIChE annual meeting (Miami beach, FI, USA, 1995).

Eliyahu, N. \& Ludmer, Z. in SIM annual meeting (Society for Industrial Microbiology, Fairmont, San Jose, CA, USA, 1995).

Eliyahu, N. \& Ludmer, Z. in SIM annual meeting (Society for Industrial Microbiology, Fairmont, San Jose, CA, USA, 1995).

Frenkel, J. Kinetic theory of liquids (Dover, New York, 1946).

Gale, G. R., Smith, A. B. \& Walker, E. M. J. Diethyldithiocarbamate in treatment of acute cadmium poisoning. Annals of Clinical and Laboratory Science 11, 476-483 (1981).

Gallo, D., Merendino, A., Keizer, J. \& Vittozzi, L. Acute toxicity of two carbamates to the Guppy (Poecilia reticulata) and the Zebrafish (Brachydanio rerio). The Science of the Total Environment 171, 131-136 (1995).

Greer, S. C. Liquid-liquid critical phenomena. Accounts of Chemical Research 11, 427-432 (1978).

Griswold, J., Chu, P. L. \& Winsauer, W. O. Phase equilibria in ethyl alcohol-ethyl acetatewater system. Industrial and Engineering Chemistry 41, 2352-2358 (1949).

Hales, B. J., Bertrand, G. L. \& Hepler, L. G. Effects of third components on critical mixing in the water-triethylamine system. The Journal of Physical Chemistry 70, 3970-3975 (1966).

Hansen, L.G. The Ortho Side of PCBs - Occurrence and disposition (Kluwer Academic Publishers, 1999).

Hazardous Waste Clean-Un Information (CLU-IN) database. Available at: httn://cluin .ord 
Hong, J. \& Pintauro, P. N. Desorption-complexation-dissolution characteristics of adsorbed cadmium from Kaolin by chelators. Water, Air and Soil Pollution 86, 35-50 (1996).

Hong, J. \& Pintauro, P. N. Selective removal of heavy metals from contaminated Kaolin by chelators. Water, Air and Soil Pollution 87, 73-91 (1996).

Hooda, P. S. \& Alloway, B. J. Cadmium and lead sorption behaviour of selected English and Indian soils. Geoderma 84, 121-134 (1998).

Ivanova, E., Benkhedda, K. \& Adams, F. Determination of copper, manganese and nickel in biological samples and sea-water by flow injection on-line sorption preconcentration in a knotted reactor coupled with electrothermal atomic absorption spectrometry. Journal of Analytical Atomic Spectrometry 13, 527-531 (1998).

lyaniwura, T. T. An in vitro evaluation of the potential toxicities and interactions of carbamate pesticides. Toxicology in Vitro 3, 91-93 (1989).

Kaiser, N., Cröll, A., Szofran, F. R., Cobb, S. D. \& Benz, K. W. Wetting angle and surface tension of germanium melts on different substrate materials. Journal of Crystal Growth 231, 448-457 (2001).

Khodadoust, A. P., Suidan, M. T., Acheson, C. M. \& Brenner, R. C. Solvent extraction of pentachlorophenol from contaminated soils using water-ethanol mixtures. Chemosphere 38, 2681-2693 (1999).

Khodadoust, A. P., Reddy, K. R. \& Maturi, K. Effect of different extraction agents on metal and organic contaminant removal from a field soil. Journal of Hazardous Materials B117, 15-24 (2005).

Kim, C., Lee, Y. \& Ong, S. K. Factors affecting EDTA extraction of lead from leadcontaminated soils. Chemosphere 51, 845-853 (2003).

Koirtyohann, S. R. \& Wen, J. W. Critical study of the APCD-MIBK extraction system for atomic absorption. Analytical Chemistry 45, 1986-1989 (1973). 
Korfali, S. I. \& Davies, B. E. Speciation of metals in sediment and water in a river underlain by limeston: role of carbonate species for purification capacity of rivers. Advances in Environmental Research 8, 599-612 (2004).

Kos, B. \& Leštan, D. Chelator induced phytoextraction and In Situ soil washing of Cu. Environmental Pollution 132, 333-339 (2004).

Lackovic, K., Angove, M. J., Wells, J. D. \& Johnson, B. B. Modeling the adsorption of Cd(II) onto goethite in the presence of citric acid. Journal of Colloid and Interface Science 269, 37-45 (2004).

Lamb, J. D. \& Peterson, R. T. Coalescence extraction: A novel, rapid means of performing solvent extractions. Separation Science and Technology 30, 3237-3244 (1995).

Langer, P. Review: Persistent organochlorinated pollutants (POPS) and human thyroid. Endocrine Regulations 39, 53-68 (2005).

Lee, S. K. \& Choi, H.-S. Spectrophotometric determination of cadmium and copper with Ammonium pyrrolidinedithiocarcamate in nonionic Tween 80 micellar media. Bull. Korean Chem. Soc. 22, 463-466 (2001).

Levy, R. \& Francis, C. W. Adsorption and desorption of cadmium by synthetic and natural organo-clay complexes. Geoderma 15, 361-370 (1976).

$\mathrm{Li}, \mathrm{Z}$. \& Shuman, L. M. Extractability of zinc, cadmium, and nickel in soils amended with EDTA. Soil Science 161, 226-232 (1996).

Lupis, C.H.P. Chemical thermodynamics of materials (Elsevier Scienve Publishing Co., Inc. New York, 1983).

Lin, H.M., Yeh, C.E., Hong, G.B. \& Lee, M.J. Enhancement of liquid phase splitting of water+ethanol+ethyl acetate mixtures in the presence of a hydrophilic agent or an electrolyte substance. Fluid Phase Equilibria 237, 21-30 (2005).

Ludmer, Z., Shinnar, R. \& Yakhot, V. Solubility in binary mixtures at the immiscibility critical point. AIChE Journal 33, 1776 (1987). 
Ludmer, Z., Shinnar, R. \& Yakhot, V. Countercurrent separation process and apparatus. Patent no. 4,954,260 (1990).

Manouchehri, N., Besancon, S. \& Bermond, A. Major and trace metal extraction from soil by EDTA: Equilibrium and kinetic studies. Analytica Chimica Acta 559, 105-112 (2006).

Martinez, E., Gros, M., Lacorte, S. \& Barcelo, D. Simplified procedures for the analysis of polycyclic aromatic hydrocarbons in water, Sediments and Mussels. Journal of Chromatography A 1047, 181-188 (2004).

Mulligan, C. N., Yong, R. N. \& Gibbs, B. F. An evalutation of technologies for the heavy metal remediation of dredged sediments. Journal of Hazardous Materials 85, 145-163 (2001).

Nardella, A., Massetti, F., Sisto, R. \& Tomaciello, R. Clean-up of polluted wet soils by solvent extraction. Environmental Progress 18, 243-249 (1999).

Peters, R. W. Chelant extraction of heavy metals from contaminated soils. Journal of Hazardous Materials 66, 151-210 (1999).

Polettini, A. et al. A kinetic study of chelant-assisted remediation of contaminated dredged sediment. Journal of Hazardous Materials B137, 1458-1465 (2006).

Polettini, A., Pomi, R. \& Rolle, E. The effect of operating variables on chelant-assisted remediation of contaminated dredged sediment. Chemosphere 66, 866-877 (2007).

Remediation Technologies Screening Matrix and Reference Guide, Version 4.0 (FRTR database). Available at: http://www.frtr.gov.

Rogachev, I. et al. Synthesis, properties, and use of copper-chelating amphiphilic dithiocarbamates as synergists of oxidant-generating herbicides. Pesticide Biochemistry and Physiology 60, 133-145 (1998).

Rowlinson, J. S. Liquid-liquid mixtures (Plenum, New York, 1969).

Saim, N., Dean, J. R., Abdullah, M. P. \& Zakaria, Z. Extraction of polycyclic aromatic hydrocarbons from contaminated soil using Soxhlet extraction, pressurised and atmospheric microwave-assisted extraction, supercritical fluid extraction and accelerated solvent extraction. Journal of Chromatography A 791, 361-366 (1997). 
Semer, R. \& Reddy, K. R. Evaluation of Soil Washing process to remove mixed contaminants from a sandy loam. Journal of Hazardous Materials 45, 45-57 (1996).

Song, Y. F., Jing, X., Fleischmann, S. \& Wilke, B.-M. Comparative study of extraction methods for the determination of PAHs from contaminated soils and sediments. Chemosphere 48, 993-1001 (2002).

Sporring, S., Bøwadt, S., Svensmark, B. \& Björklund, E. Comprehensive comparison of classic Soxhlet extraction with Soxtex extraction, ultrasonification extraction, supercritical fluid extraction, microwave assisted extraction and accelerated solvent extraction for the determination of polychlorinated biphenyls in soil. Journal of Chromatography A 1090, 1-9 (2005).

Sun, B., Zhao, F. J., Lombi, E. \& McGrath, S. P. Leaching of heavy metals from contaminated soils using EDTA. Environmental Pollution 113, 111-120 (2001).

Tadmor, M., Lantsman, B. \& Ludmer, Z. in Ninth European congress on biotechnology (Brussels, Belgium, 1999).

Tran, Y. T., Barry, D. A. \& Bajracharya, K. Cadmium desorption in sand. Environmental International 28, 493-502 (2002).

Treybal, T. E. Liquid extraction (McGraw-Hill, New York, 1963).

Ullmann, A., Ludmer, Z. \& Shinnar, R. Phase transition extraction using solvent mixtures with critical point of miscibility. AIChE Journal 41, 488-500 (1995).

Ullmann, A., Ludmer, Z. \& Shinnar, R. Novel continuous multistage extraction column based on phase transition of critical-solution mixtures. Chemical Engineering Science 52, 567-581 (1997).

US Environmental Protection Agency. EPA 905-B94-003 (Chicago III: Great Lakes National Program Office, 1994).

US Environmental Protection Agency. Innovative site remediation technology, Vol. 3 - Liquid extraction technologies. EPA, 542-B97-006 (1998).

Vladimirova, N., Malagoli, A. \& Mauri, R. Diffusion-driven phase separation of deeply quenched mixtures. Physical Review E 58, 7691-7699 (1998). 
Walas, S. M. Phase equilibria in chemical engineering (Butterworth Publishers, 1985).

Warwick, P., Hall, A., Pashley, V., Van der Lee, J. \& Maes, A. Zinc and cadmium mobility in sand: Effects of $\mathrm{pH}$, speciation, cation exchange capacity (CEC), humic acid and metal ions. Chemosphere 36, 2283-2290 (1999).

Webb, M. The Chemistry, Biochemistry and biology of cadmium (ed. Webb, M.) (Elsevier/North-Holland Biomedical Press, 1979).

Whitburn, J. S., Wilkinson, S. D. \& Williams, D. R. Chemical speciation of Ethylenediamine$\mathrm{N}, \mathrm{N}$-disuccinic acid (EDDS) and its metal complexes in solution. Chemical Speciation and Bioavailability 11, 85-93 (1999).

Zeng, Q. R., Sauvé, S., Allen, H. E. \& Hendershot, W. H. Recycling EDTA solutions used to remediate metal-polluted soils. Environmental Pollution 133, 225-231 (2005). 